\title{
Response of Scutellarin Content to Heavy Metals in Erigeron Breviscapus
}

\author{
Huabin Xiong, Changqun Duan, Xinxiang A, and Minghong Chen
}

\begin{abstract}
Part of hypotheses point out the quantity of plant secondary metabolites will increase in order to adapt environmental stress. Secondary metabolites accumulation of scutellarin in Erigeron breviscapus was investigated under different heavy metal stress. The results showed that exposure to cadmium, chromium and mercury stress scutellarin content of stem was higher sometimes, but its change from stress of copper and arsenic were opposite. In leaf and flower, scutellarin concentration was also decrease rapidly. So we inferred that after toxic substances entry into plant body, level of some secondary metabolites will exhibit decrease trend in some extent, and not only enhanced any time. Therefore, the change of secondary metabolites in medicine plant should attract more attention under stress environment in future.
\end{abstract}

Index Terms-Inhibit, scutellarin, secondary metabolites, stress.

\section{INTRODUCTION}

The secondary metabolites are the products from plant itself that adapt to surrounding environment during the long-term course of evolution. Meantime, plant could accommodate oneself to changes for environment and enhance survival capabilities that are its essential ecological function in changed natural environment, especially environmental stress. Among them, the product of secondary metabolites which can protect plant from surrounding environment is rather important. That is to say, secondary metabolites play a crucial function in the adaptation of plants to the alternative environmental, and can synthesis quantities of secondary metabolites with limitless ability. Some biotic and abiotic stress factors, such as low temperature, strongly light intensity, poor nutrition elements, water deficit and microbial attack, will reduce plant defence mechanisms and motivate many complex biochemical process [1]. Changes have been reported at genetic or protein level that is brought about by stress conditions and are reflected in a profound alteration of the metabolite pool of the affected plants [2]-[5].

Therefore, some hypotheses of generation mechanism of secondary metabolites are presented, like growth/ differentiation balance (GDB) [6], carbon/nutrient balance

Manuscript received December 10, 2012; revised March 1, 2013. This work was supported by the National Natural Science Foundation of China (U1133604 and 31070456), the Science and Technology Program of Educational Department of Yunnan Province, China (2010Z073), and Open Research Fund of Key Laboratory of Chemistry in Ethnic Medicinal Resources (Yunnan University of Nationalities), State Ethnic Affairs Commission \& Ministry of Education, P.R. China (MZY1302).

Huabin Xiong, Changqun Duan and Huabin Xiong are with Institute of Environmental Science and Ecological Restoration \& Key Laboratory for Conservation and Utilization of Bio-Resource of Yunnan, Yunnan University, China (e-mail: 344192363@qq.com; cn-ecology@126.com).

Xinxiang $\mathrm{A}$ is with Biotechnology and Germplasm Research Institute, Yunnan Academy of Agriculture Sciences, China.
(CNB) [7], optimum defense (OD) [8] and resource availability (RA) [9]. What's more important, these four hypotheses have confirmed that the quantities of plant secondary metabolites exposure to environmental stress will enhance. Moreover, Holopaninen [1] and Szathmary [4]also point out that despite the complex nature and inconclusive reports on the regulatory mechanisms and biosynthesis of different secondary metabolites in plants, a significant body of research evidence indicates that their biosynthesis and accumulation remain remarkably under the control of the environment.

In plants for medical excessive heavy metals will effect its normal growth and development, and accumulate secondary metabolites. It is found that through the correlation analysis of content of secondary metabolites and trace elements content of aucubin is closely correlation with arsenic in different Scrophularian ningpoensis, it suggested that arsenic is link with synthesis of aucubin [10]. The content of lead and mercury in all geoherbs, like Coptis chinensis, Coptis deltoidea, Ligusticum chuanxiong, Fritillaria cirrhosa, Gastrodia elata, Curcuma aromtica, Citrus aurantium, Ophiopogon jupnicus, Aconitum carmichaeli, Angelica dahurica var. fromosana and Codonopsis var. modesta, which are higher than other non-geoherbs from Sichuan province, China [11]. The synthesis and accumulation of artemisinin are obvious enhanced when the concentration of cadmium arrive to $0.15 \mathrm{mg} \mathrm{kg}^{-1}$ [12]. Hence, the research of the changes of secondary metabolites for medical plant from heavy metal is rather essential.

Erigeron breviscapus is a common medicine plant in traditional Chinese medicine that mainly grown in Yunnan province of Southwest China [13]. It has a long time used in remedy brain thrombosis and associated paralysis, coronary arteriosclerosis and myocardial ischemia through enhancing blood circulation, preventing blood coagulation and dilating brain blood vessels, especially as a long-range therapeutic drug without evident side effects [14]-[15]. The previous research indicated that scutellarin is one of the most important active constituents in Erigeron breviscapus [16].

In order to analysis influence of secondary metabolites accumulation from stress environment the content change of scutellarin in Erigeron breviscapus was investigated under different heavy metal stress, and which will also offer some benefit introduction for its cultivar how to select appropriate soil environment.

\section{MATERIALS AND METHOdS}

\section{A. Pot Experiment}

Pot-test experiments were conducted in Yuhua campus 
(24 50'39" North latitude and $102^{\circ} 51^{\prime} 09^{\prime \prime}$ East longitude) of Yunnan University of Nationalities between November, 2011 and July, 2012. The soil used was collected from an orchard in suburban Kunming, China. And it was collected from surface horizon $(0-15 \mathrm{~cm})$, air-dried, crushed, passed through a $5 \mathrm{~mm}$ sieve and mixed well with heavy metals. There were four treatments with three replicates for each heavy metal (Table I). Meantime, each plastic pot filled with $35 \mathrm{~kg}$ prepared soil incubated for 30 days after adding heavy metal was watered with tap water daily to maintain 3 to $4 \mathrm{~cm}$ submergence throughout experiment period. When there were 2-3 leaves, the prepared seedlings of Erigeron breviscapus were transplanted to soil. The pots were laid out in the greenhouse and watered twice or thrice for one week to maintenance moderate soil moisture. The sample was harvested until flower dead (Fig. 1).

TABLE I: ORIGIN AND CONCENTRATION OF HEAVY METALS USED IN THE TESTED SOIL

\begin{tabular}{|c|c|c|c||}
\hline \multirow{3}{*}{ Treatment } & \multicolumn{4}{|c|}{ Treatment element / } \\
\cline { 2 - 4 } & $\mathrm{Cr} / \mathrm{K}_{2} \mathrm{Cr}_{2} \mathrm{O}_{7}$ & $\mathrm{Cd} / \mathrm{CdCl}_{2} .2 .5 \mathrm{H}_{2} \mathrm{O}$ & $\mathrm{Cu} / \mathrm{CuSO}_{4} .5 \mathrm{H}_{2} \mathrm{O}$ \\
\hline $\mathrm{T}_{0}$ & 0 & 0 & 0 \\
\hline $\mathrm{T}_{1}$ & 10 & 0.5 & 10 \\
\hline $\mathrm{T}_{2}$ & 50 & 2 & 50 \\
\hline $\mathrm{T}_{3}$ & 100 & 5 & 100 \\
\hline
\end{tabular}

Continue

\begin{tabular}{|c|c|c||}
\hline \multirow{2}{*}{ Treatment } & \multicolumn{2}{|c|}{$\begin{array}{c}\text { Treatment element / } \\
\text { molecular formula of origin substances }\left(\mathrm{mg} \mathrm{kg}^{-1}\right)\end{array}$} \\
\cline { 2 - 3 } & $\mathrm{Pb} / \mathrm{Pb}\left(\mathrm{NO}_{3}\right)_{2}$ & $\mathrm{Hg} / \mathrm{HgCl}_{2}$ \\
\hline $\mathrm{T}_{0}$ & 0 & 0 \\
\hline $\mathrm{T}_{1}$ & 50 & 0.5 \\
\hline $\mathrm{T}_{2}$ & 100 & 2 \\
\hline $\mathrm{T}_{3}$ & 200 & 5 \\
\hline
\end{tabular}

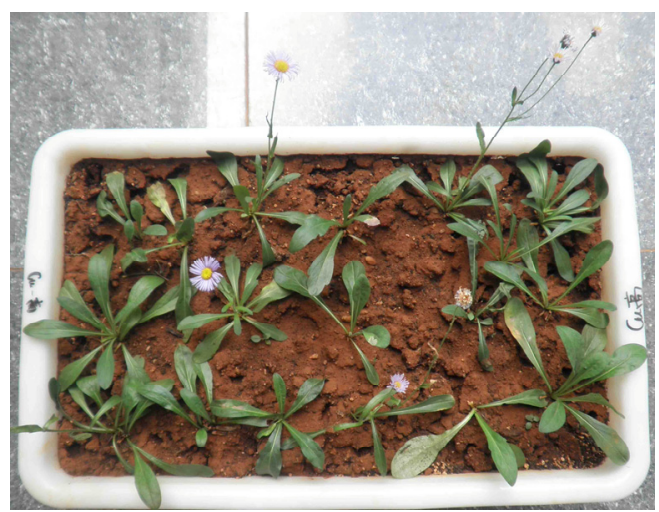

Fig. 1. Pot experiment of different heavy metal stress

\section{B. Extraction of Scutellarin}

The stem, leaf and flower tissues of Erigeron breviscapus were dried at room temperature and then ground to 80 mesh powders. The sample (50mg) was immersed with $60 \mathrm{ml} 80 \%$ methanol for 30 minutes, then, extracted with the supernatants 30 minutes $\left(60^{\circ} \mathrm{C}\right.$ and $\left.59 \mathrm{KHz}\right)$. After the procedure was complete the extract volume was increased to $100 \mathrm{ml}$ with adding $80 \%$ methanol. The extract was filtered with filter paper, and $3 \mathrm{ml}$ liquid was transferred into colorimetric ware ( $1 \mathrm{~cm}$ diameter). Scutellarin concentration was measured with ultraviolet spectrophotometer in $335 \mathrm{~nm}$ wavelength. The following standard working solutions with concentrations in the range of $0-0.015 \mathrm{mg} \mathrm{mL}^{-1}$ for scutellarin were obtained. In this study, the yield of scutellarin [17] was defined:

Yield of scutellarin $\left(\mathrm{mg} . \mathrm{kg}^{-1}\right)=\frac{\text { mass of scutellari n extracted }}{\text { mass of material }}$

\section{Data Analysis}

In order to analysis the content of scutellarin from heavy metal stress and uncontaminated soil, relative difference (RD) was used.

$$
R D(\%)=\frac{\left(T-T_{0}\right) \times 100}{T_{0}}
$$

where: $\mathrm{T}$ was scutellarin concentration of every treatment under five heavy metals stress respectively and $T_{0}$ was scutellarin concentration in non-population soil.

\section{RESUlTS AND DisCUSSION}

As increasing demand of phytomedicines in the all world, quality of medicine plant is attracting more interesting for its excellent therapy with no side effect. But, it is clear that quality in medicine plant include two important parts, the first one is good food safety of medicine plant, that is, all toxic substances in these plants are satisfied to international food standard and not bring any damage to human health. And the second one is good medicine quality, which will guarantee its therapy to disease and not delay to improve human health.

However, with the rapid progress of all global economy, numerous of toxic substances, such as heavy metals and environmental hormones, have been detected in water, soil and food. Therefore, many research focusing on absorption, accumulation and transformation from soil and water to plant have been conducted from the begin of last century. But, to medicine plant, can stress from toxic substances influence accumulation of secondary metabolites, or even change major medicine substances content? In order to illustrate the phenomenon, scutellarin content change was investigated exposure to five differential heavy metals.

\section{A. Scutellarin Content Change of Stem}

TABLE II: SCUTELLARIN CONTENT CHANGE OF STEM UNDER HEAVY METALS STRESS

\begin{tabular}{||c|c|c|c|c||}
\hline \hline Treatment & $\mathrm{Cd}$ & $\mathrm{Cr}$ & $\mathrm{Hg}$ & $\mathrm{Cu}$ \\
\hline $\mathrm{T} 1$ & 1.5666 & -24.2820 & 27.1540 & -12.2715 \\
\hline $\mathrm{T} 2$ & 11.4883 & 34.9869 & -46.7363 & -1.8277 \\
\hline $\mathrm{T} 3$ & -29.5039 & -11.2272 & 12.5326 & -9.9217 \\
\hline
\end{tabular}

\begin{tabular}{|c|c|}
\hline \multicolumn{1}{|c|}{ Continue } \\
\hline Treatment & $\mathrm{Pb}$ \\
\hline $\mathrm{T} 1$ & -32.3760 \\
\hline $\mathrm{T} 2$ & -36.8146 \\
\hline $\mathrm{T} 3$ & -31.0705 \\
\hline
\end{tabular}

When the cadmium concentration is low than $2 \mathrm{mg}^{-\mathrm{kg}^{-1}}$ in soil, change of scutellarin content in stem is not very obvious, but with increase of cadmium content the decreasing degree of scutellarin is rather distinguish and excess one quarter of 
control. Similarly, under chromium and mercury stress scutellarin content in stem is almost all reduced and even arrives to half of control in some concentration. Besides, as $\mathrm{T}_{2}$ and $\mathrm{T}_{1}$ in Table II show, copper and lead added artificially to soil respectively, scutellarin content in stem exhibited described decrease trend in spite of any metal concentration.

\section{B. Scutellarin Content Change of Leaf}

TABLE III: SCUTELLARIN CONTENT CHANGE OF LEAF UNDER HEAVY Metals StRess

\begin{tabular}{||c|c|c|c|c||}
\hline \hline Treatment & $\mathrm{Cd}$ & $\mathrm{Cr}$ & $\mathrm{Hg}$ & $\mathrm{Cu}$ \\
\hline $\mathrm{T}_{1}$ & -7.2597 & -21.9836 & -14.5194 & -9.1002 \\
\hline $\mathrm{T}_{2}$ & 1.9427 & -47.1370 & -21.8814 & -3.2720 \\
\hline $\mathrm{T}_{3}$ & -50.3067 & -19.3252 & 3.0675 & 0.0000 \\
\hline
\end{tabular}

Continue

\begin{tabular}{||c|c||}
\hline \hline Treatment & $\mathrm{Pb}$ \\
\hline $\mathrm{T}_{1}$ & -7.6687 \\
\hline $\mathrm{T}_{2}$ & -0.5112 \\
\hline $\mathrm{T}_{3}$ & -3.3742 \\
\hline
\end{tabular}

In leaf of Erigeron breviscapus, scutellarin content is only minor increase when cadmium and mercury concentration are $2 \mathrm{mg} \mathrm{kg}^{-1}$ and $5 \mathrm{mg} \mathrm{kg}^{-1}$ according to Table III, respectively. Oppositely, on the condition of other concentration and metal elements scutellarin content is a negative growth, it is inferred that scutellarin synthesis is inhibited seriously.

\section{Scutellarin Content Change of Flower}

TABLE IV: SCUTELLARIN CONTENT CHANGE OF FLOWER UNDER HEAVY METALS STRESS

\begin{tabular}{|c|c|c|c|c|}
\hline Treatment & $\mathrm{Cd}$ & $\mathrm{Cr}$ & $\mathrm{Hg}$ & $\mathrm{Cu}$ \\
\hline $\mathrm{T}_{1}$ & -29.3383 & -33.9576 & -13.6080 & -38.9513 \\
\hline $\mathrm{T}_{2}$ & -44.9438 & -47.8152 & -65.9176 & -26.5918 \\
\hline $\mathrm{T}_{3}$ & -75.4057 & -30.7116 & -32.8340 & -42.5718 \\
\hline \multicolumn{5}{|l|}{ Continue } \\
\hline Treatment & $\mathrm{Pb}$ & & & \\
\hline $\mathrm{T}_{1}$ & -32.8340 & & & \\
\hline $\mathrm{T}_{2}$ & -58.4270 & & & \\
\hline $\mathrm{T}_{3}$ & -27.5905 & & & \\
\hline
\end{tabular}

Under every concentration of all metal elements stress scutellarin content were reduce severely in flower. The decreasing degree of scutellarinis higher than in stem and leaf and the maximum value arrive to 65 percentages. The result is shown clearly in Table IV.

\section{The Further Discussion}

The result of this study show Erigeron breviscapus can cause some change in some extent within different heavy metals stress scutellarin content of different tissues. And the total trend is reduced, especially in leaf and flower tissues. Concurrently, it is inferred that although some toxic substances in condition of low dose can promote plants growth and secondary metabolites accumulate in mentioned extent [18]-[19], the increasing level of secondary metabolites is very limited. Such as the concentrations of five flavone components in $S$. baicalensis Georgi were not significantly affected by spiking low concentrations of As $\left(\leq 200 \mathrm{mg} \mathrm{kg}^{-1}\right.$ ) into soils, but high levels of As inhibited the generation of baicalin and wogoninside [20]. Therefore, the increase of secondary metabolites by addition of toxic substances is very difficult, and its effect is mainly brought some poison to plants.

In synthesis of optimum defense the generation of secondary metabolites is reduce chance of plant growth pay a price. Plant growth is very slow under environment stress, and has a low cost for generation of secondary metabolites. Compensatory ability for damaged in plant is very low, defense benefit of secondary metabolites is promoted. So, plant would produce more secondary metabolites in stress condition. In addition, according to the results of study we speculate that this phenomenon is depend on that plant growth is affected slightly. If damage and time of stress have been become more seriously, all defense system would deplete extremely energy to maintain longer life, and the increasing level of secondary metabolites will very difficult.According to resource distribution strategy, every plant is three important functions, which include growth, maintain survival and propagation. But if plant encounter environmental stress in the course of growth and development, resource distribution strategy will change to adapt to alternative environment, function of maintain survival also will become major aim. Therefore, with the purpose of adapt to environmental change and survival in further, plant will activate secondary metabolites defense system and synthesis a great deal of secondary metabolites to defense disadvantage and extreme environment. Thus, in order to guarantee excellent medicine quality of plant for medicine in contaminated soil will not adopt to cultivar medicine plants.

On the other hand, some trace metal ion, like magnesium, zinc and iron, they are essential elements of enzyme synthesis, and these material in plant can affect secondary metabolites' change. When they are higher than a normal condition, plant would not toxic severely. Instead, some secondary metabolites, especially key medicinal components, will massive synthesis [21]-[23]. Therefore, the research how to influent synthesis of secondary metabolites in high concentration condition of trace elements will very hot focus in future.

In the research secondary metabolites of Erigeron breviscapus only analysis change of scutellarin content, but from the secondary metabolites prospective, secondary metabolites category that have been changed under heavy metal stress should very rich. Hence, in order to research change rule of secondary metabolites after exposure to toxic substances, research objects of secondary metabolites will not only focus on known and interesting metabolites substances, but also investigate deeply category and quantities of all changed metabolites, so all these work will help to master plant response mechanism for stress environment.

For example, using a combination of HPLC-ESI-MS techniques, during cold acclimation a total of 40 phenolic and flavonoid compounds in wheat (Triticum aestivum L.) leaves were identified. Moreover, the trimethylated flavone, 3', 4', 5'-trimethyltricetin was identified for the first time in the native extracts of both control and cold-acclimated wheat leaves [24]. Yukino Yakabe reported first that some 
compounds for formation of furanocoumarin phytoalexins could be induced in Glehnia littoralis root cultures by treatment with ascorbic acid (AsA), and the modulation of the phytoalexin biosynthetic pathway in G. Littoralis be induced also by iron deficiency [25].

In short, the formation of medicine plant quality is link closely with plant living surrounding, in which medicine plant have been evolve and adapt to the environment for hundreds of years, even thousands of years. Therefore, in order to explain formation mechanism of quality, growth surrounding of medicine plant should pay the more attention, especially on the stress environment condition.

For the discovery of novel and innovative drugs, the wide chemical diversity of secondary metabolites represents an extremely rich biogenic resource throughout the plant kingdom [5]. Therefore, several schools of thought, substantiated with numerous scientific evidence, implicate the highly ordered interactions between plants and their biotic and abiotic environments as being a major driving force behind the emergence of specific secondary metabolites [26].

\section{ACKNOWLEDGMENT}

This work was financially supported by the National Natural Science Foundation of China (U1133604 and 31070456), the Science and Technology Program of Educational Department of Yunnan Province, China (2010Z073), and Open Research Fund of Key Laboratory of Chemistry in Ethnic Medicinal Resources (Yunnan University of Nationalities), State Ethnic Affairs Commission \& Ministry of Education, P.R. China (MZY1302).

\section{REFERENCES}

[1] J. K. Holopainen and J. Gershenzon, "Multiple stress factors and the emission of plant VOCs," Trends in Plant Science, vol. 15, no. 3, pp. 176-184, June, 2010.

[2] J. L. Dangle and J. D. G. Jones, "Plant pathogens and integrated defence responses to infection," Nature, vol. 411, pp. 826-833, June, 2001.

[3] F. Loreto and J. P. Schnitzler, "Abiotic stresses and induced biogenic volatile organic compounds," Trends in Plant Science, vol. 15, pp. 154-166, 2010.

[4] E. Szathmáry, F. Jordán, and C. Pál, "Can genes explain biological complexity,” Science, vol. 292, pp. 1315-1316, June, 2001.

[5] B. Ncube, J. F. Finnie, and J. V. Staden. "Quality from the field: The impact of environmental factors as quality determinants in medicinal plants," South African Journal of Botany, vol. 82, pp. 11-20, September, 2012

[6] P. M. Frischknecht, K. Schuhmacher, H. M. Scharer, W. Baumann, "Phenotypic plasticity of Senecio vulgaris from contrasting habitat types: growth and pyrrolizidine alkaloid formation, "J Chem Eco, vol. 27, no. 2, pp. 343-358, February, 2001.

[7] J. G. Hamilton, A. R. Zangerl, E. H. DeLucia, and M. R. Berenbaum, "The carbon-nutrient balance hypothesis: its rise and fall," Ecol Let, vol. 4, pp. 86-95, January, 2001.

[8] E. K. Barto, D. Cipollini, "Testing the optimal defense theory and the growth-differentiation balance hypothesis in Arabidopsis thalian," Oecologia, vol. 146, no. 2, pp. 169-178, December, 2005.

[9] J. E. Byers, "Effects of body size and resource availability on dispersal in a native and a non-native estuarine snail," J Exp Mar Biol Ecol, vol. 248, no. 2, pp. 133-150, May, 2000.

[10] J. Yu, "Studies on establishing and optimizating standard quality system of Scrophularian ningpoensis Hemsl," M.S. thesis, Northwest Agricultural and Forestry University, Yanglin, China. May, 2009.

[11] J. A. Fan, S. P. Yi, S. R. Li, B. Z. Zhou, "The correlation analysis of geoherbs and trace elements in Sichuan," Journal of Chinese Medicinal Materials, vol. 14, no.1, pp. 3-5, January, 1991.
[12] X. L. Han, L. Q. Huang, L. P. Guo, M. J. Li, X. H. Liu, and X. B. Zhang, "Accumulation and translocation of cadmium in soil and plant and its effects on growth of Artemisia annua and artemisinin content," China Journal of Chinese materia Medica, vol. 35, no. 13, pp. 1655-1659, July, 2010.

[13] H. Liu, X. L. Yang, T. Ren, Y. D. Feng, and H. B. Xu, "Effects of Erigeron breviscapus ethanol extract on neuronal oxidative injury induced by superoxide radical," Fitoterapia, vol. 76, no. 7-8, pp. 666-670, December, 2005.

[14] Y. J Wu, Y. Jin, H. Y. Ding, L. J Luan, Y. Chen, and X. S. Liu, "In-line monitoring of extraction process of scutellarin from Erigeron breviscapus (vant.) Hand-Mazz based on qualitative and quantitative uses of near-infrared spectroscopy," Spectrochimica Acta, Part A, vol. 79, no. 55, pp. 934-939, September, 2011.

[15] M. Gao, M. Gu, and C. Z. Liu, "Two-step purification of scutellarin from Erigeron breviscapus (vant. Hand. Mazz.by high-speed counter-current chromatography," Journal of Chromatography B, vol. 838, no. 2, pp. 139-143, July, 2006.

[16] H. B. Huang, W. F. Bao, F. F. Yang, Y. Jia, K. Li, "Study on chemical constituents of Erigeron breviscapus (Vant.) Hand-Mazz," J. Shenyang Pharm. Univ. vol. 18, no. 4, pp. 266-267, July, 2001.

[17] M. Gao, W. Huang, M. RoyChowdhury, and C. Z. Liu, "Microwave-assisted extraction of scutellarin from Erigeron breviscapus Hand-Mazz and its determination by high-performance liquid chromatography," Analytica Chimica Acta, vol. 591, no. 2, pp. 161-166, May, 2007.

[18] L. Q. Huang, L. P. Guo, "Secondary metabolites accumulating and geoherbs formation under environmental stress," China Journal of Chinese materia Medica, vol. 32, no. 4, pp. 277-280, February, 2007.

[19] X. F. Yan, Y. Wang, and Y. M. Li, "Plant secondary metabolism and its response to environment," Acta ecologica sinica, vol. 27, no.6, pp. 2554-2561, June, 2007.

[20] H. B. Cao, Y. Jiang, J. J. Chen, H. Zhang, W. Huang, L. Li, and W. S. Zhang, "Arsenic accumulation in Scutellaria baicalensis Georgi and its effects on plant growth and pharmaceutical components," Journal of Hazardous Materials, vol. 171, no. 1-3, pp. 508-513, November, 2009.

[21] L. P. Guo, L. Q. Huang, and Y. N. Yan, "The influences of inorganic elements in soil on the geolism of Atractylodes lancea," China J. Chin. Mater. Med., vol. 27, no. 4, pp. 245-250, April, 2002.

[22] R. Verpoorte, "Metabolic Engineering of Plant Secondary Metabolism," KLUWER academic publishers, 2000, pp. 295-297.

[23] D. H. Liu, L. P. Guo, L. Q. Huang, H. Jin, W. Liu, and D. W. Zhu, "Effects of mineral nutrition on metabolism of flavonoids in medicinal plants," China Journal of Chinese materia Medica, vol. 35, no. 18, pp. 2367-2371, September, 2010.

[24] A. Moheb, R. K. Ibrahim, R. Roy, and F. Sarhan, "Changes in wheat leaf phenolome in response to cold acclimation," Phytochemistry, vol. 72, no. 18, pp. 2294-2307, December, 2011.

[25] Y. Yakabe, M. Terato, A. Higa, K. Yamada, and Y. Kitamura, "Iron availability alters ascorbate-induced stress metabolism in Glehnia littoralis root cultures," Phytochemistry, vol. 74, pp. 100-104, February, 2012.

[26] P. Facchini, "Plant secondary metabolism: out of the evolutionary abyss," Trends in Plant Science, vol. 4, pp. 382-384, 1999.

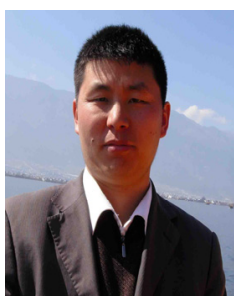

Huabin Xiong was born in China. He was awarded his Bachelor's and Master's Degrees in Biotechnology and Plant Genetic Breeding respectively from the Department of Biotechnology, Faculty of Agronomy and Biotechnology, Yunnan Agricultural University, China in 1998 and 2005, respectively.

$\mathrm{He}$ is now a $\mathrm{PhD}$ student at the Institute of Environmental Science and Ecological Restoration \& Key Laboratory for Conservation and Utilization of Bio-Resource of Yunnan, Yunnan University, China. And he is also a Lecturer in the school of Chemistry and Biotechnology at the Yunnan Universities of Nationalities. His research interests are adaption and evolution of plant to abiotic stress, transformation and accumulation of heavy metal in plant.

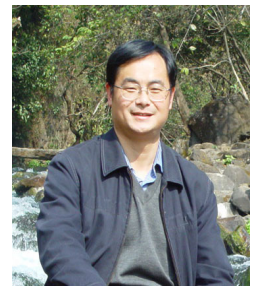

Changqun Duan was born in China in 1966 and obtained PhD degree in 1994. He is as a professor working in the school life Sciences at the Yunnan University, China. He holds Dianchi Lake project of Lake Theme by supported National Key Scientific and Technological Projects. He is a member of Environment Science in Colleges and Universities Steering Committee for working Ministry of 
Education of the People's Republic of China and Vice director of Education committee of Ecological Society of China. His research interests include biological adaption, evolution and specialization and change and micro evolution of biodiversity in pollution environment, ecology procedure, ecological remediation and reclamation of water environment degradation in Plateau Lake, food security, ecological safety, analysis of environmental security, economic research of natural protection and pollution prevention and control.

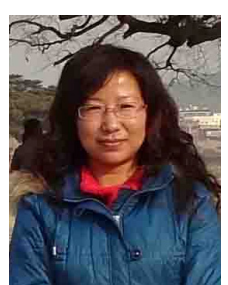

Xinxiang A was born in China in 1977. She is now a research assistant at Biotechnology and Germplasm Research Institute, Yunnan Academy of Agriculture Sciences, China. Her research Major Field is Genetics Study and Exploitation of Useful Genes in Crop Germplasm Resources.

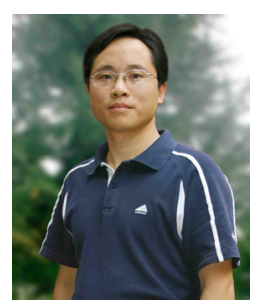

Minghong Chen was born in China in 1974. He is now a vice professor at the Yunnan Universities of Nationalities, China. His research interests lie in biodiversity of plant genetic resource and genetic breeding of medicine plant. 